\title{
A SITE-BASED PRACTICAL IMPROVISATION FOR THE ANALYTICAL DETERMINATION OF ASPECT RATIO
}

\author{
Rajesh Gopinath¹, Deepak D.G. ${ }^{2}$ \\ ${ }^{1}$ Department of Civil Engineering, BMS Institute of Technology and Management, Bengaluru, India \\ ${ }^{2}$ BMS School of Architecture, Bengaluru, India \\ ${ }^{1}$ dr.rajeshgopinathnair@gmail.com
}

\begin{abstract}
'Aspect Ratio', a commonly used indicator to describe typical urban geometry is computed as the average ratio of the building heights ' $\mathrm{H}$ ' to the canyon width ' $\mathrm{W}$ '. Its determination techniques in the present urbanization scenario is bound by certain assumptions which falter as most cities across globe does not project a well-planned street profile. An urban canyon factor is of most significance in climatic and air quality studies.

The study showcases how the standard assumptions cited in literatures for Urban Morphological Analysis cannot apply to most urban canyons in any townships that have evolved rampantly. The present research recommends a rationally feasible methodology of analytically ascertaining and representing Aspect Ratio for variant street canyons. The research objective envisaged selection of 3 random locations encompassing heterogeneous street canyon geometries. At each of these locations its land-use pattern and road network was mapped for a radius of $250 \mathrm{~m}$ by supervised-classification to assist in extracting the canyon geometry features, namely building height and road width across all the streets.

The revised methodology judiciously delves upon when stations also have plots without pre-defined boundaries for creation of layouts. The logic encompasses complete dimensional analysis, and accounts for all four directions, the dynamic road width and building length measured along street about each focal point. The present research recommends this technique for a study of any magnitude; and encompassing just a street or even an entire city; as it's practically applicable to any site condition and does away with errors due to the 'idealistic' assumptions.
\end{abstract}

\section{Keywords}

Aspect, canyon, dimensional, elevation, ratio, urban.

\section{Introduction}

A typical urban morphology is often projected as an urban canyon comprised of the walls of adjacent buildings, the street between them and the air volume enclosed within it (Nicholson Sharon, 1975). 'Aspect Ratio', a commonly used indicator; is computed as the average ratio of the building heights ' $\mathrm{H}$ ' to the canyon width ' $\mathrm{W}$ ' (Oke, 1988a). 'Aspect Ratio' is hence also denoted as $\mathrm{H}: \mathrm{W}$ (Steyn, 1980).

The profiling of an urban canyon is based on the universally accepted 'Classification of Canyons' as Avenue (Figure 1), Regular (Figure 2), Narrow (Figure 3), and Deep (Figure 4); i.e. based on the Aspect Ratio values as $<0.5,1,>1$ and $>2$ respectively (Afiq et. al, 2012).

\section{Rationale for Study}

Several researchers have tried to establish the relationship of canyon geometry for a city with its Climatic variations (Yamashita et.al, 1986; Oke, 1981; Gopinath,
2014), Energy balance (Marciotto et.al, 2010; Oke, 1988b), Wind flow pattern (Chang and Meroney, 2003), Air quality (Chan et.al, 2003) etc. The present research postulates that, as long as the street geometry is restricted to urban micro-climate studies (single/isolated monitoring points); the cited assumptions are more or less sufficient. However, if the ambit extends to a macro-level with a single representative value from a multitude of $\mathrm{H}: \mathrm{W}$ values, then the existing logics in literatures do not suffice (Gopinath et.al, 2014) thereby demanding further research in improvisation for better representation of canyon framework in terms of $\mathrm{H}: \mathrm{W}$, and the present study attempts to resolve this research lacunae.

\section{Research Methodology}

The research objective envisaged selection of 3 random locations encompassing heterogeneous mix of street canyon geometries ranging from wide to deep, in Bengaluru, India. 


\section{Architecture and Engineering Volume 2 Issue 3}

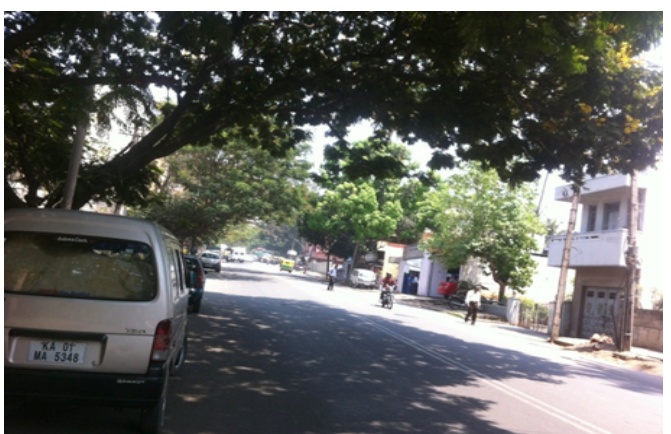

a

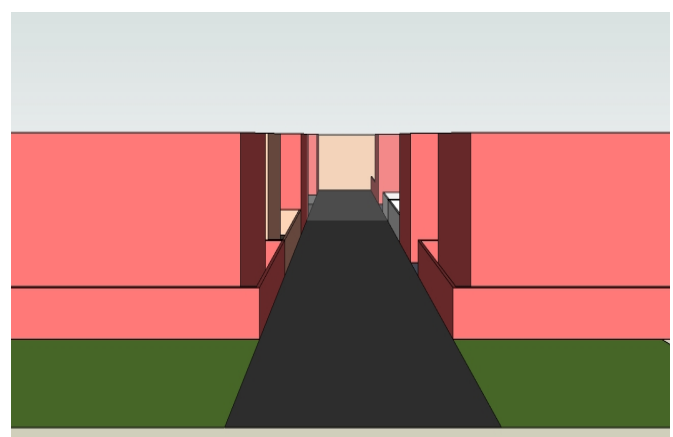

b

Figure 1. An Avenue Canyon: a - A Typical Avenue Canyon; b-Representation of a typical Avenue Canyon

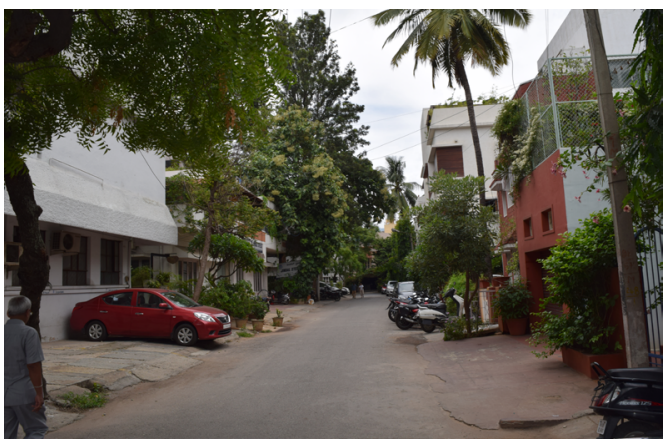

a

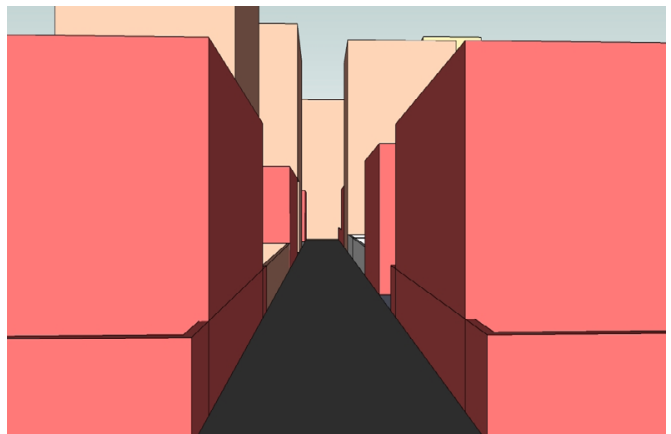

b

Figure 2. A Regular Canyon : a - A Typical Regular Canyon ; b - Representation of a typical Regular Canyon

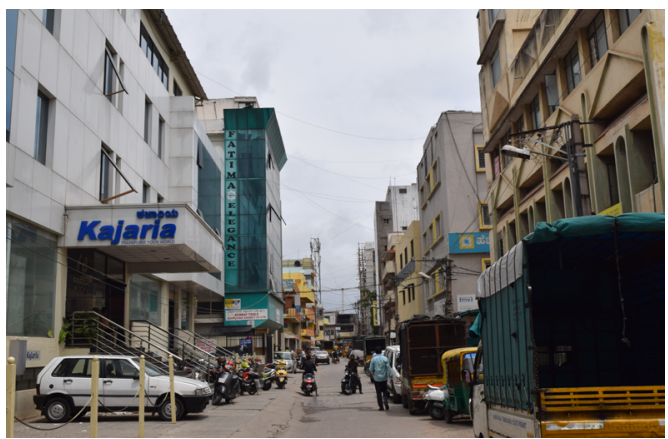

a

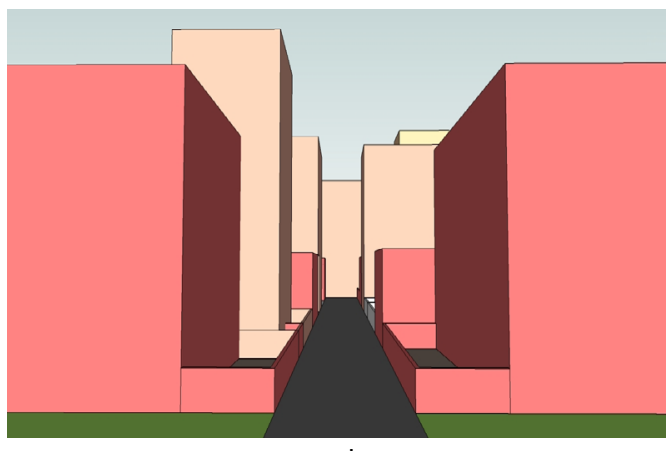

b

Figure 3. A Narrow Canyon : a - A Typical Narrow Canyon ; b - Representation of a typical Narrow Canyon

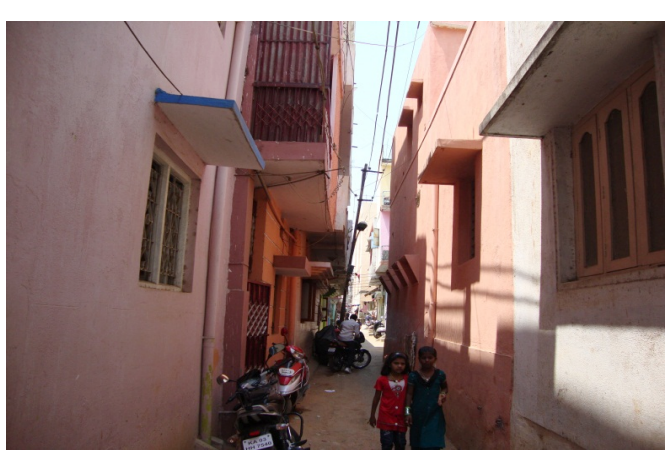

a

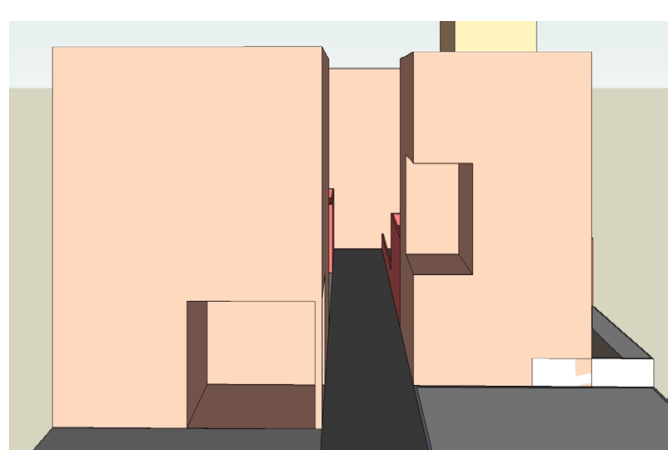

b

Figure 4. A Deep Canyon : a - A Typical Deep Canyon; b - Representation of a typical Deep Canyon 
At each of these locations its land-use pattern and road network was mapped for a radius of $250 \mathrm{~m}$ by supervised-classification to assist in extracting the canyon geometry features, namely building height and road width across all the streets. Further the canyon geometry across these stations was logically reasoned for Aspect Ratio with logics cited in literatures. Figures 5 to 7 highlight the extracted "urban-fabric" along with legend (Figure 8) for the 3 sample stations in Bengaluru (India).

\section{Inferential Outlook}

As may be observed, these extracted features showcase an outright preview of non-applicability for the prime assumption made in urban climatology i.e., "the streets are uniform and of infinite length, with same height buildings laid in a well-planned phased manner" (Nicholson, 1967). Primarily it is obvious that this prime assumption can only be applicable to township profiles with idealistic and well-planned canyons (Figures 5a, $5 b$ \& 5c); and eventually ignores contributions from within urban canyons with buildings that are scattered very close to each other (Figure 6a), or non-uniformly (Figure 7a), or with 'abrupt' canyons (Figure 9).

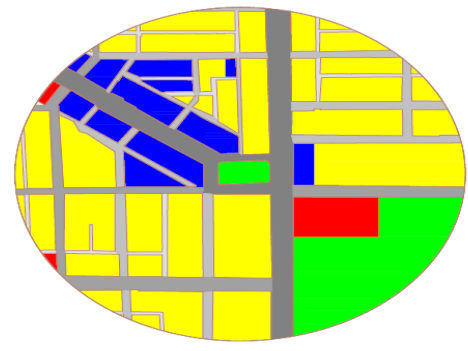

a

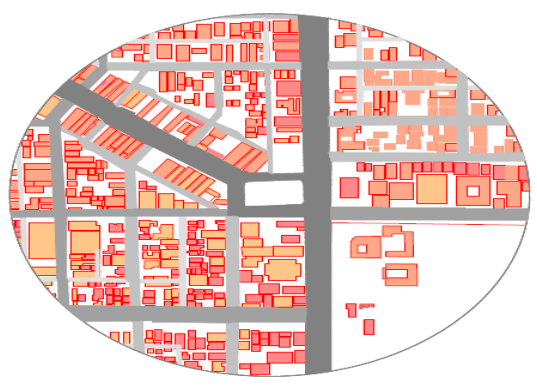

b

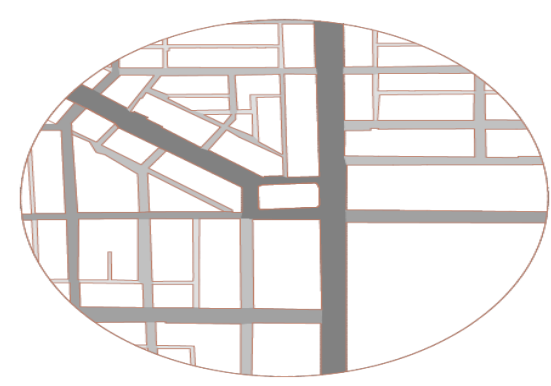

c

Figure 5 (a, b, c). Land-use, Building-height and Road Network of a well-planned locality in Bengaluru

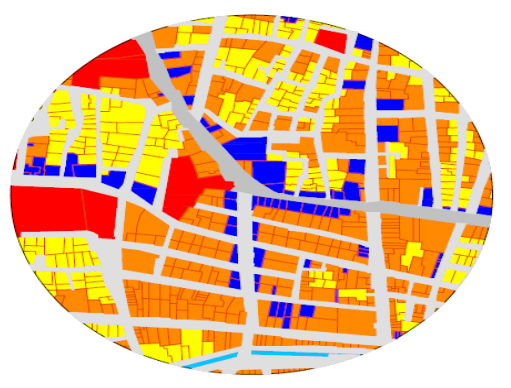

a

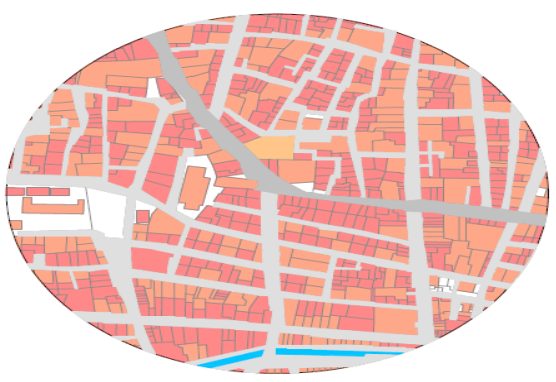

b

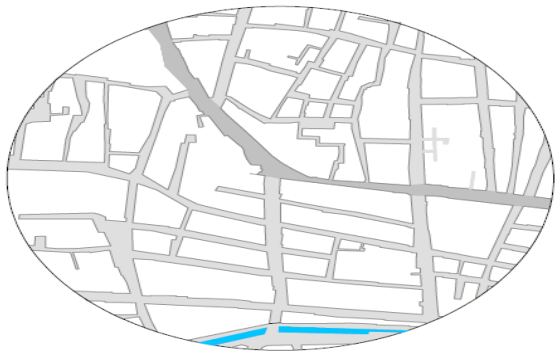

C

Figure $6(\mathrm{a}, \mathrm{b}, \mathrm{c})$. Land-use, Building-height and Road Network of an ill-planned locality in Bengaluru

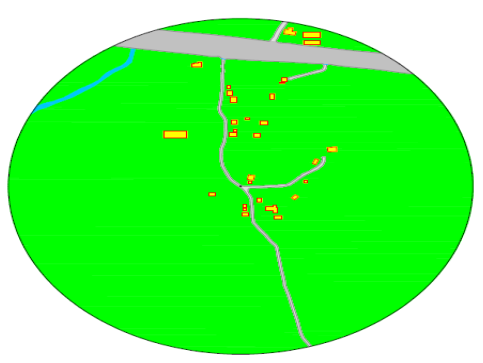

a

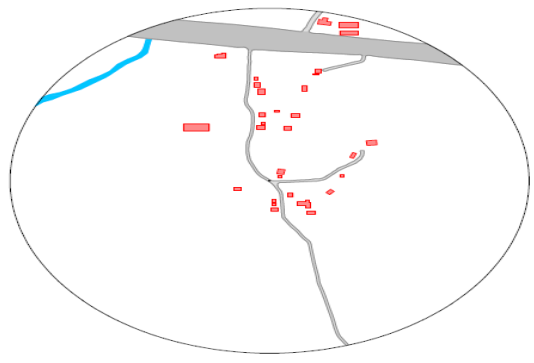

b

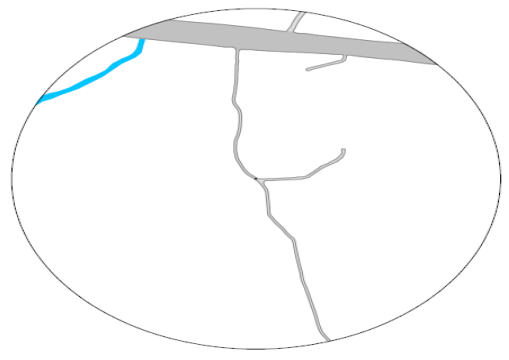

C

Figure $7(a, b, c)$. Land-use, Building-height and Road Network of a peri-urban locality in Bengaluru 


\begin{tabular}{|c|l|}
\hline \multicolumn{2}{|c|}{$\begin{array}{l}\text { LAND USE MAP } \\
\text { LEGEND }\end{array}$} \\
\hline & PUBLIC /SEMI- PUBLIC \\
\hline & RESIDENTIAL \\
\hline & COMMERCIAL \\
\hline & PARK / OPEN SPACES \\
\hline & MIXED LAND USE \\
\hline & NALA \\
\hline
\end{tabular}

a

\begin{tabular}{|l|l|}
\hline \multicolumn{2}{|c|}{$\begin{array}{c}\text { BUILDING HEIGHT } \\
\text { LEGEND }\end{array}$} \\
\hline & GROUND / GOUND+1 \\
\hline & GROUND+2 / GROUND+3 \\
\hline & GROUND+4 / GROUND+5 \\
\hline
\end{tabular}

b

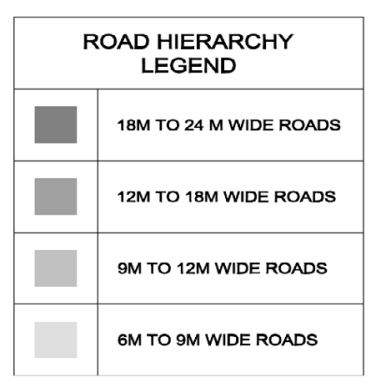

C

Figure 8 (a, b, c). Legends for Land-use, Building-height and Road Network for Figures 3, 4, 5

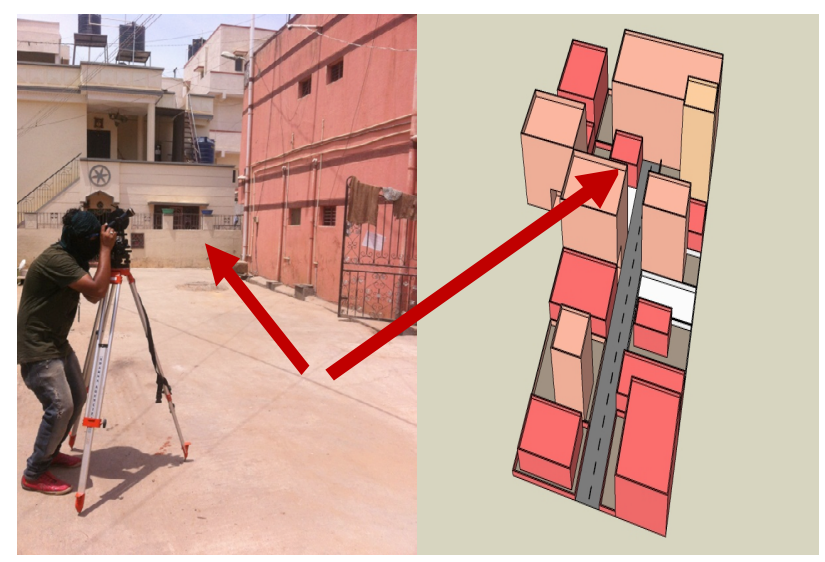

Figure 9. An Abrupt Canyon

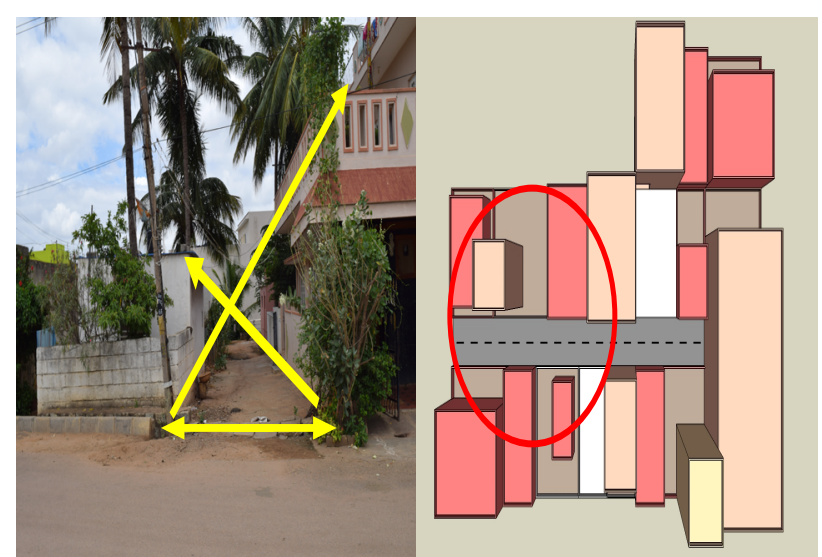

Figure 10. Sample inorganic Canyon Layout 
In the present urbanization context; the cited assumption falters especially in developing and underdeveloped nations wherein most cities does not project a well-planned profile in terms of their building framework (Figure 6b) or street alignments (Figure 6c). Hence, even the underdeveloped layouts are at a similar risk (Figure $7 \mathrm{~b}$ and Figure 7c).

This argument was defended by extracting a random layout from the station depicting inorganic canyon profile. Processing of Figure 4c to obtain canyon profiling about each street; revealed that there were certain streets wherein the buildings were constructed as and at deadends (Figure 9), irregularly (Figure 10) and very often with variable heights (Figure 11). Hence these clearly depict violation of "uniform canyon \& uniform building height" theory. Figure 12 also signifies the non-applicability of the definition of canyon that has been deftly incepted to urban studies as "a street with buildings lined up continuously along both sides" (Oke, 1981).

There exists streets in Bengaluru (India) wherein there are random open spaces facing the buildings, which due to legal reasons can sustain as so, for several years and decades to follow. This situation triggers two potential debates. First, under these circumstances can the classification of canyons as 'short', 'medium' and 'long' (Afiq et. al, 2012) be applicable? The length of canyon $(L)$ and height ' $H$ ' illustrates the street canyon as Short when $\mathrm{L} / \mathrm{H}=3$, as Medium when $\mathrm{L} / \mathrm{H}=5$ and as Long when $\mathrm{L} / \mathrm{H}=7$ (Ahmad, 2005). Second, whether this urban situation can even be termed as a canyon? Geographically speaking canyon is "a shallow portion with steep abutments on 'either' sides".
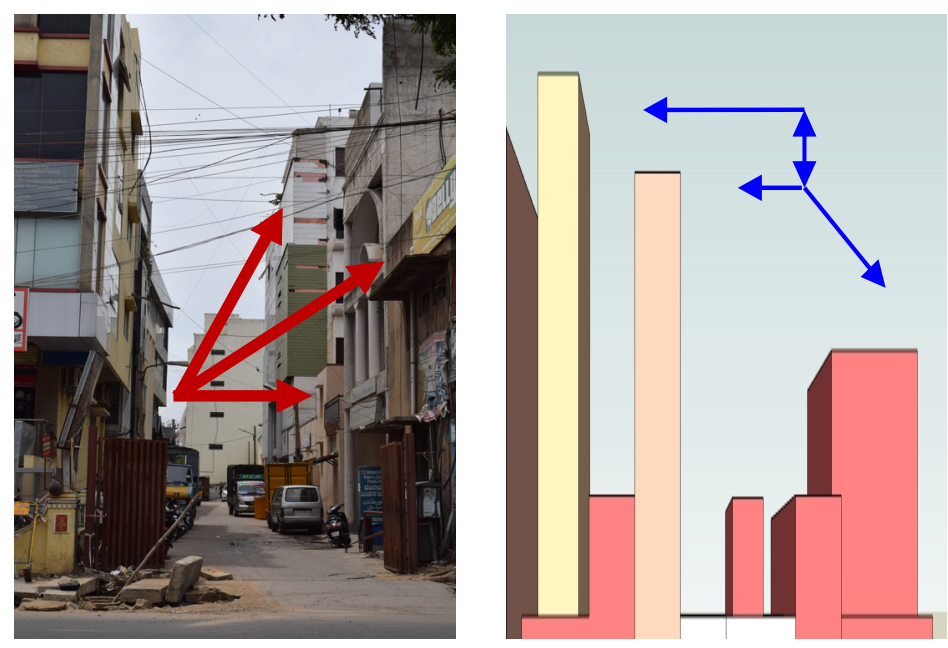

Figure 11. Irregular Building heights
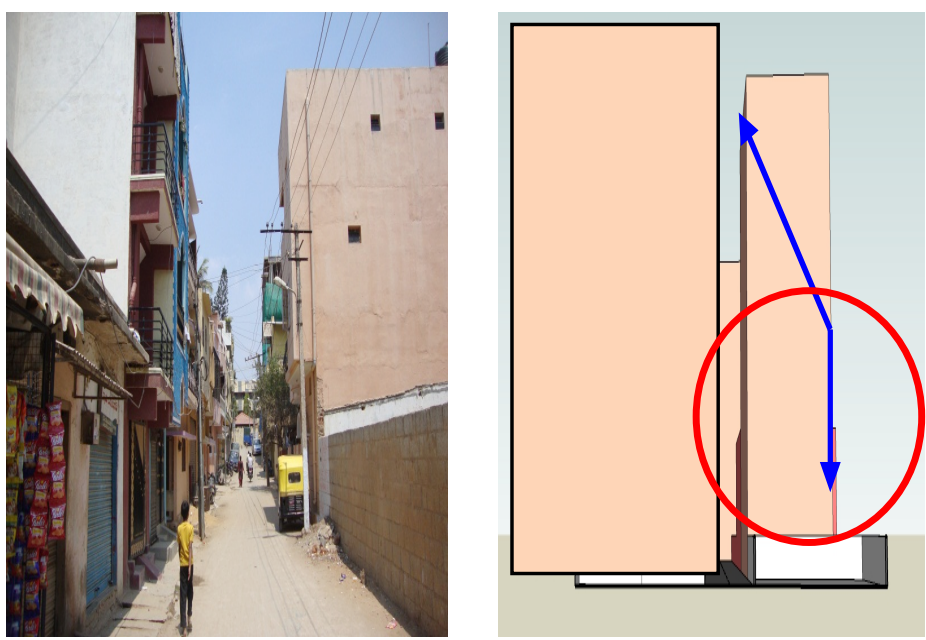

Figure 12. Tall buildings facing Empty site 
For further introspection; the influence of a 'Deep' canyon in practicality can be marginalized due to differential heights of houses facing each other. For instance, the practical value of $>2$ can be achieved if an undeveloped or vacant plot is facing a very 'tall' building as depicted in Figure 12. A further addendum to this issue is the dwarfing effect from two more site-based situations. Firstly, wherein a tall building exists behind an empty site that faces a street, as depicted in Figure 13. Secondly, when the building that's constructed behind an existing house is much taller than it, as depicted in Figure 14.

The practical act of shifting the observatory in researches have been oriented about randomly or approximating at the mid-point of home's total length. This is a concern since, the concept of fixed length of houses (dimension as measured along streets) is not a reality even in a modernized metropolitan such as Bengaluru (India) that hold plots of varying and irregular dimensions. Hence errors may creep in due to the relative deviation of the facing heights observed along oppositely facing buildings. This may be due to factors such as the wall-edges of oppositely facing houses are not at $0^{\circ}$ with each other (Figure 15), or when the adjoining houses share a common load-bearing wall (Figure 16), and this situation may also arise in case of an empty site facing a house (Figure 12).

To summarise the findings from site-based conditions, the idealised site-based conditions are far from what the developed, developing and underdeveloped nations pres- ent under the guise of Urbanisation upon their townships (Rajesh Gopinath et.al, 2015). Consequently, the assumption for 'urban canyon' does not apply to all townships, and hence their application in climate research and air quality studies can introduce erroneous outcomes.

Therefore to overcome the limitations posed by complex urban configuration, the present study has developed a 'logic-based' improvised computation tool for any township irrespective of its 'canyon' geometry and components. The same is presented as Equation 1:

$$
\frac{H}{W}=\frac{\left(\frac{\sum H_{i} \times L_{i}}{\sum L_{i}}\right)}{\left(\frac{\sum W_{i}}{n}\right)}
$$

Herein ' $H_{i}$ ' is the mean of 'derived' heights from all directions about each measuring point, ' $L$ ' is the distance between each observatory, ' $W$ ' is the width of full street for every observatory on the carriageway, and ' $n$ ' is the number of times the observatory has been shifted for taking 'angle of elevation'.
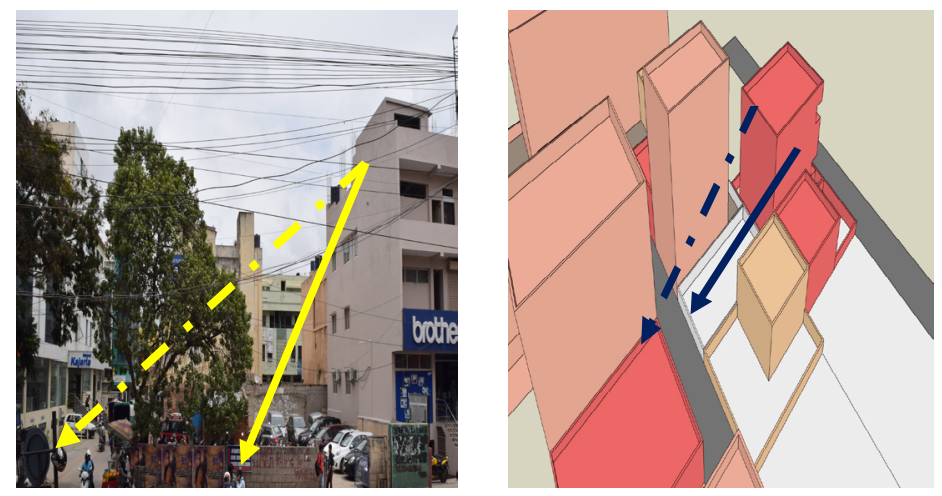

Figure 13. Dwarfing effect on empty site
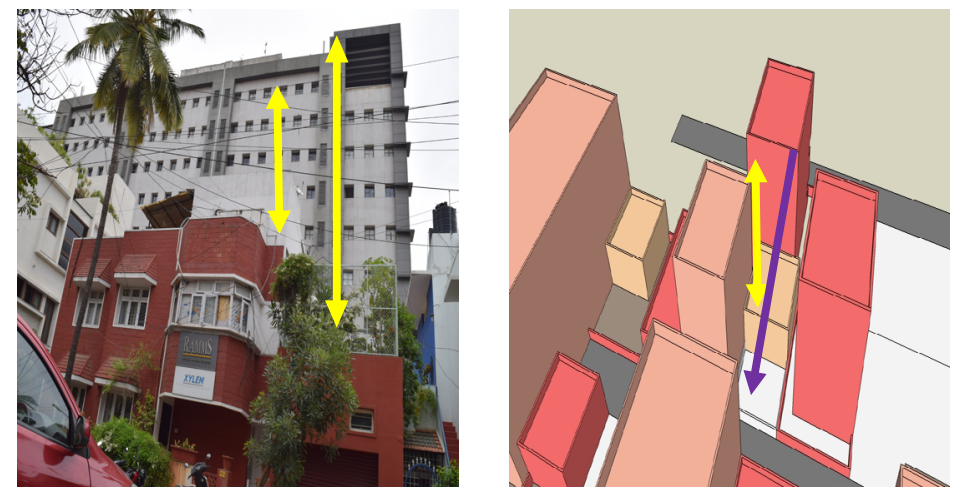

Figure 14. Dwarfing effect on house 


$$
H_{i}=\left(\operatorname{Tan} \alpha_{i} \times W_{i}\right)+S_{i}
$$

The logic for deriving mean ' $\mathrm{H}$ ' is depicted in Equation 2 , wherein $W_{i}$ refers to width of the road and ' $s_{i}$ ' is the respective intercept. In literatures, the respective mean of $H_{1}$ and $H_{2}$, and the sum of $W_{1}$ and $W_{2}$, methodology facilitates to obtain Aspect Ratio (Oke, 1988b). The revised logic however has considered all directions irrespective of the presence or absence of buildings, and hence multiple angles of elevation $\left(\alpha_{i}\right)$ ought to be measured above 'lineof-sight'. Subsequently, the angles of elevation measured alongside axis of street could be or may not be $0^{\circ}$ about each observatory, subjected to presence or absence of an abrupt canyon. This improvisation is based on the argument that an abrupt canyon has a skewed $\mathrm{H}: \mathrm{W}$ and hence must be included wherever applicable. In this context, it is to be also noted that in certain literatures the value of ' $W$ ' was not practically quantified and was considered as uniform about each measuring point along the entire canyon (Chen-Yi Sun et.al, 2009). This is especially a setback in case of most streets in Bengaluru (India) wherein width of carriageway is dynamic.

The study also ignores the effect of edges (Equation 3). The improvised logic (Figure 18) overcomes these limitations, as it strives to shift observatory w.r.t. edge of buildings (Figure 17); and not mid-point of each building length. Also the methodology always maintains focal point on street itself; thereby overcoming hurdles offered by taller buildings overlooking empty sites and shorter buildings. Hence, this ensures contribution of the 'taller' house as well to H:W.
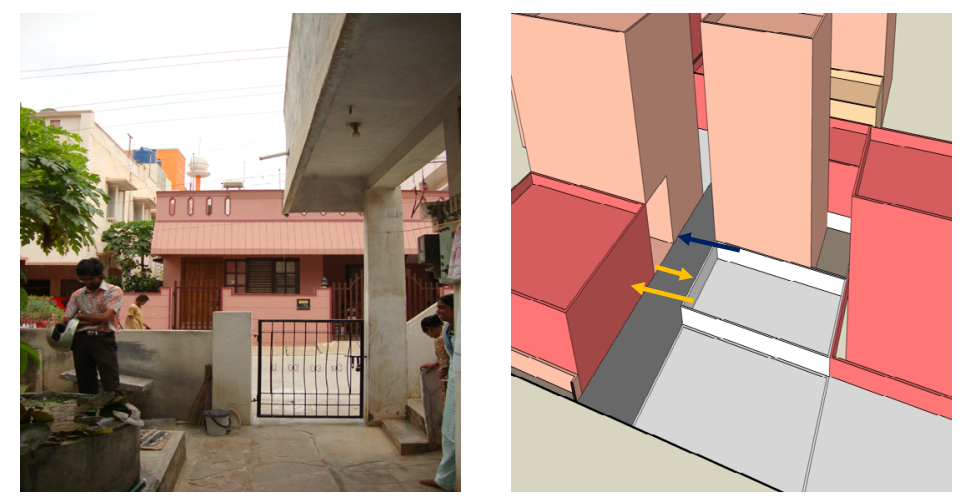

Figure 15. Sample Street View
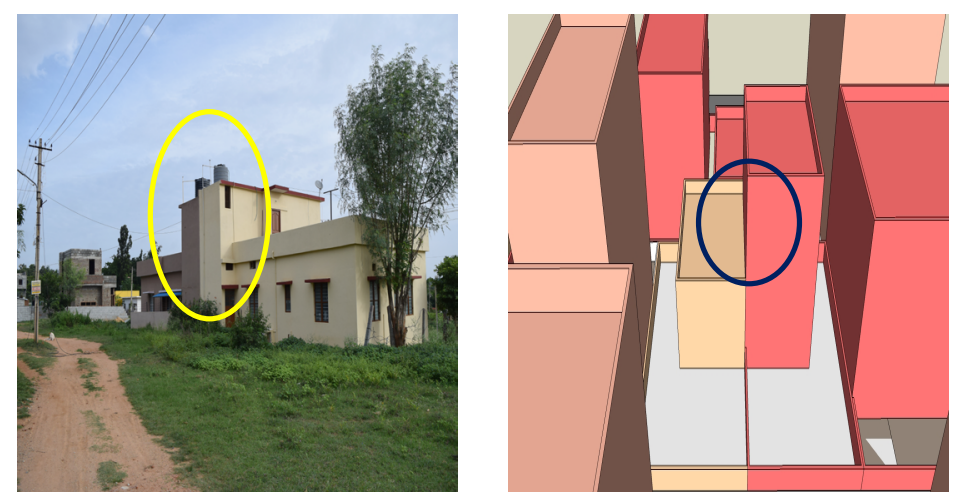

Figure 16. Sample Street View

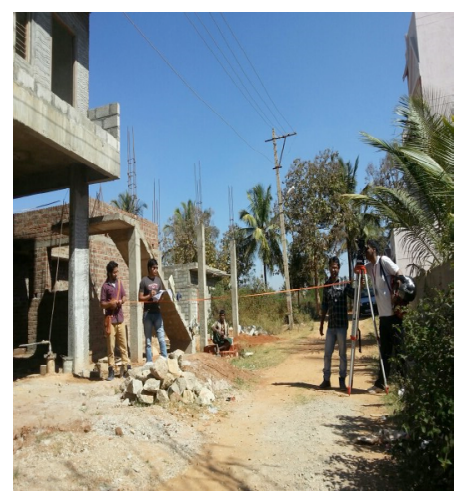

Figure 17. Edge and site based measurements

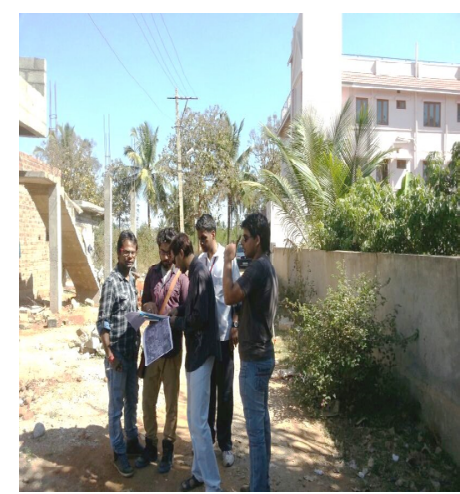

Figure 18. Supervised Classification 


\section{Architecture and Engineering Volume 2 Issue 3}

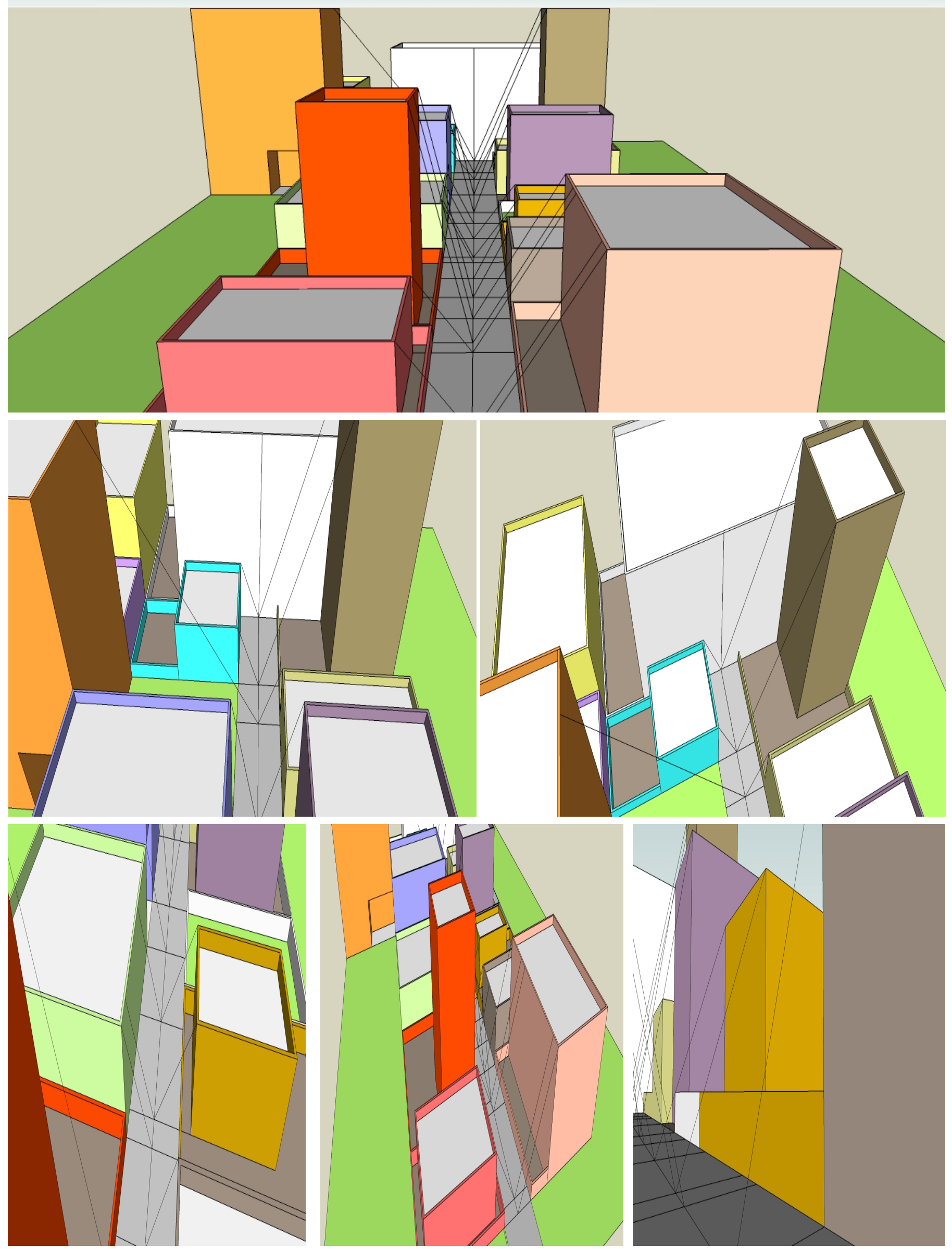

Figure 19. Compilation of artistic impression for Methodology as per Revised Logic by Authors 


$$
H / W=(\Sigma H i \times D i) /(\Sigma D i) / W
$$

This revised logic and methodology needs to be judiciously worked upon when stations also have plots without pre-defined boundaries for creation of layouts. For this the latest town map or updated google satellite images needs to be procured and adequately analyzed for effective supervised classification on site (Figure 18). On a macroscale aspect, this was magnanimously ignored in the literatures, as the focus was laid only on developed urban canyons. Also the representative Aspect Ratio value for a station was often considered to be the largest value (Marlos et.al, 2013) thereby potentially reflecting at the effect of outliers. Herein by this new-logic, the representative Aspect Ratio shall be a mean of all $\mathrm{H}: \mathrm{W}$ contributory values, and also the addition of undeveloped observatories will eventually dip the $\mathrm{H}: \mathrm{W}$ value.

\section{Conclusion}

The H:W ratio basically describes how tightly or loosely spaced the buildings are with respect to their heights. Its determination techniques in the present urbanization scenario is bound by certain assumptions which falter as most cities across globe does not project a well-planned street profile. In the present research a logically-improvised analytical approach has been described which precisely estimates Aspect Ratio. The present research recommends this technique for a study of any magnitude; and encompassing just a street or even an entire city; as it's practically applicable to any site condition and does away with errors due to the 'idealistic' assumptions. 


\section{References}

Afiq, W.M.Y., Azwadi, C.S.N., Saqr, K.M. (2012). Effects of Buildings Aspect Ratio, Wind Speed and Wind Direction on Flow Structure and Pollutant Dispersion in Symmetric Street Canyons: A Review. International Journal of Mechanical and Materials Engineering, 7(2), pp. 158-165.

Ahmad, K., Khare, M., Chaudhry, K.K. (2005). Wind Tunnel Simulation Studies on Dispersion at Urban Street Canyons and Intersections-A Review. Journal of Wind Engineering and Industrial Aerodynamics, 93 (9), pp. 697-717. DOI: 10.1016/j. jweia.2005.04.002

Chan, A.T., Au, W.T.W., So, E.S.P. (2003). Strategic Guidelines for Street Canyon Geometry to Achieve Sustainable Street Air Quality-Part II: Multiple Canopies and Canyons. Atmospheric Environment, 37 (20), pp. 2761-2772. DOI: 10.1016/ S1352-2310(03)00252-8

Chang, C.H., Meroney, R.N. (2003). Concentration and Flow Distributions in Urban Street Canyons: Wind Tunnel and Computational Data. Journal of Wind Engineering and Industrial Aerodynamics, 91(9), pp. 1141-1154. DOI: 10.1016/S0167-6105(03)00056-4

Chen-Yi Sun et.al. (2009). A Thermal Environment Investigation Of The Urban Street Canyon In A Hot And Humid City, Taichung City, Taiwan. In: Proceedings of The seventh International Conference on Urban Climate. Yokohama, Japan.

Eeftens, M. et.al. (2013). Quantifying urban street configuration for improvements in air pollution models. Atmospheric Environment, 72, pp. 1-9. DOI: 10.1016/j.atmosenv.2013.02.007

Gopinath, R. et al. (2014). An Analytical and Practically Feasible improvisation over representation of Sky-View-Factor. American International Journal of Research in Formal, Applied \& Natural Sciences, 6(2), pp. 147-150.

Gopinath, R. et.al (2015). Change Recognition in Land-Cover Dynamics for Bengaluru (India) City due to Rampant Urbanization, using Quantum G.I.S. International Journal of Engineering, Business and Enterprise Applications, 13(1), pp. 34-36.

Gopinath, R., Akella, V., Bhanumurthy, P.R. (2014). Influence of Bengaluru (India)'s Canyon Geometry on the Intra-Urban Ambient Air Temperature. Scientific Herald of the Voronezh State University of Architecture and Civil Engineering, 23(3), pp. 40-50.

Marciotto, E., Oliveira, A.,Hanna, S. (2010). Modeling Study of the Aspect Ratio influence on Urban Canopy Energy Fluxes with a Modified Wall Canyon Energy Budget Scheme. Building and Environment, 45(11), pp. 2497-2505. DOI: 10.1016/j. buildenv.2010.05.012

Nicholson, S.E. (1967). A Pollution Model for Street-Level Air. Atmospheric Environment, 9, pp.19-31. DOI: 10.1016/0004-6981(75)90051-7

Oke, T.R. (1981). Canyon Geometry and the Nocturnal Urban Heat Island: Comparison of Scale Model and Field Observations, International journal of Climatology, 1 (3), pp. 237-254. DOI: 10.1002/joc.3370010304

Oke, T.R. (1988a). Street Design and Urban Canopy Layer Climate. Energy and Buildings, 11(1-3), pp. 103-113. DOI: 10.1016/0378-7788(88)90026-6

Oke, T.R. (1988b). The Urban Energy Balance. Progress in Physical Geography, 2(4), pp. 471-508. DOI: 10.1177/030913338801200401

Steyn, D.G. (1980). The Calculation of View Factors from Fish-Eye Lens Photographs. Atmosphere-Ocean, 18 (3), pp. $254-258$. DOI: 10.1080/07055900.1980.9649091

Yamashita, S., Sekine, K., Shoda, M., Yamashita, K., Hara, Y. (1967). Studies on Relationships between Heat Island and Sky View Factor in the Cities of Tama River Basin, Japan. Atmospheric Environment, 20(4), pp. 681-686. DOI: 10.1016/0004-6981(86)90182-4 